\title{
Re-pensando la Antropología desde el Sur
}

Re-thinking Anthropology from the South

\author{
Eloy Alfaro* \\ Universidad de Cuenca - Ecuador \\ zancudo.irreverente@gmail.com
}

Mientras se prepara este dossier, el mundo de habla hispana es testigo, de las respuestas que la Espańa de la Conquista, aquella que aun en el siglo XXI tiene reyes, reinas y nobleza, da al pedido que hiciera Manuel López Obrador (AMLO), actual presidente de México a la Monarquía Española. Que pidan disculpas por el desastre que dejaron después de la llegada de Colón a este continente, no es un disparate, es apenas una señal de reconocimiento de un mundo distinto donde existen otros. Antes en la colonia como ahora en la era digital, Espańa y Europa ponen de manifiesto aquello que el mundo desarrollado no abandona, esa condición que les lleva a pensarse así mismos como el primer mundo, desconociendo lo demás. Este pensarse primer mundo cubre todos los campos del saber y el conocer, las Ciencias Sociales no están fuera de ello.

Sin embargo, desde el sur hay otras formas de ver y entender el mundo. La apuesta de este Dossier se orienta en mostrar diversos trabajos antropológicos que reflexionan desde matrices teóricas y prácticas propias el entorno y la sociedad que les rodea. La Antropología que se hace desde el Sur, se caracteriza porque en su práctica se desmarca de los conceptos y entendidos que definen la ciencia del primer mundo, así: No están claras las distancias entre sujeto (investigador) y objeto (seres humanos investigados); los conceptos no pretender ser universales; los antes objetos de estudio, ahora son sujetos de pensamiento; la naturaleza no es un ajeno, sino parte del territorio, la vida y el cuerpo social; se es parte de los procesos y no un observador, etc.

Está claro que, desde el Sur, no hay posibilidad de pensarse el mundo con y desde una sola matriz de pensamiento, con y desde un solo cuerpo teórico. La apuesta de este Dossier de Antropología, también se orienta a desarrollar, incentivar y poner en evidencia, otras formas de construir y hacer pensamiento provenientes de sectores subalternos, indígenas, academias, gremios, que se piensan a si mismos como posibilidad de ser; pero además jubilados norteamericanos que buscan espacios con mejores condiciones de vida en los cuales terminar la suya.

Entendida la Antropología latinoamericana como una ciencia despojada del aura occidental, es sujeto y objeto de la ciencia a la vez, es decir no sólo la entiende e interpreta, sino que se compromete con la realidad social, política, humana de su entorno. Un elemento clave para entender la razón, es la separación entre el ser humano y la naturaleza o de la sociedad y el mundo que lo rodea; en esto juega mucho

*Antropólogo, Master en Antropología por FLACSO Ecuador, como Investigador Social ha publicado artículos académicos, en temas de historia, cultura, filosofía y política. Como escritor ha publicado varios poemarios, actualmente es académico en la universidad de Cuenca, consultor y activista social. 
la contemplación y la admiración, que son la materia sobre la que erige el mito. En el mito se es parte de aquello que se contempla o admira. La razón en cambio contempla y admira pero no es parte de aquello admirado, se substrae, se vuelve externo a lo observado. Lo observado, el otro, que no es yo, se vuelve el objeto de mi observación de mi pensamiento, de mis ideas, esta última es el principio de la matriz occidental cuyo límite es entender el sentido de las cosas, pero no ser parte de ellas.

Partamos de la preocupación de James G. Frazer (1975) que en 1922 decía que el objeto de estudio de la etnología, los salvajes que habitan países salvajes, estaban desapareciendo. Y eso es verdad, ya no existen. El formato del mundo "salvaje y ausente de civilización" al cual había que civilizar, en realidad nunca existió. Y esa es una verdad que para el mundo occidental no logra superar de ahí la resistencia a considerarse iguales. Las ciencias sociales occidentales acostumbradas a estudiar lo exótico, lo raro, se quedan sin razón de ser. En la ciudad de Macas-Ecuador en la selva amazónica, el pueblo Shuar Arutam en el año 2018, convocó el primer encuentro entre científicos Sociales como Philipe Descola -que estudió el pueblo Shuar-, Michael Uzendoski -que estudia y vive con los Quichua, entre otros connotados intelectuales y los objetos de su estudio. Este encuentro entre los "antes salvajes" ahora intelectuales indígenas, y los no salvajes, intelectuales no indígenas europeos; es la evidencia de que el objeto de estudio de la Ciencia Social Occidental, el salvaje, el exótico, el nativo, ya no existe. Existen seres humanos, que en igualdad de condiciones teorizan y discuten las maneras de ver y ser vistos.

Desde la Antropología comprometida (aquella que busca ser parte de los procesos y el entorno y no sólo analizarlos y entenderlos externamente) entendemos que la generación de conceptos que abstraen la realidad y los hace universales, como lo hace la ciencia en general y la occidental en particular, llevan al individuo a convertirse en sujeto con capacidad de dominio, exclusión o abuso, sobre aquello que no es universal, esta ha sido la matriz común sobre la que se levanta la ciencia occidental.

Los artículos a continuación analizan los escenarios posibles y probables desde donde se realiza el ejercicio antropológico en Latinoamérica, prácticas y disciplinas se exponen. La lectura de estos artículos nos remite a pensar que es urgente desde la subalternidad, pensar en nuevos escenarios de interpretación y análisis para esta ciencia social.

Desde diversos ángulos, este número de Religación presenta artículos cuyo eje es la identidad - como expresión culinaria, como proceso de tránsito en la migración, como aporte teórico a la antropología, como imagen indígena que se proyecta y auto define- entre otros. Esto no es gratuito, responde a la urgencia de un continente en movimiento, en el que porciones de la sociedad latinoamericana, en forma de éxodos se moviliza al norte o al sur, con la principal idea en mente, ser vistos como lo que son, ciudadanos del mundo donde nadie es ilegal. Pero no es una identidad de individuo, la que se analiza, es sobre todo en tanto que perteneciente a un colectivo.

$\mathrm{Al}$ respecto Guillermo Alonso, señala que desde su punto de vista, el oficio y la sensibilidad antropológica frente a los procesos de identidad, en los actuales momentos, son puestos a prueba; obligados a repensar y proponer nuevos enfoques, escenarios 
de observación y análisis o categorías que sustenten lecturas e interpretaciones críticas de los factores culturales que están modelando las vidas de gentes y pueblos. El horizonte de trabajo actual es problemático en un mundo donde lo local no puede explicarse desmembrado de las fuerzas globales. Esto no implica renuncia alguna a la tradicional (histórica) razón de ser de la antropología, a aquellos presupuestos epistemológicos que la caracterizan como disciplina. Pues ella ha contribuido a las profundas transformaciones socioculturales y civilizatorias de la modernidad del siglo XX y del XXI, aportando evidencias y argumentos a favor de la igualdad, la libertad y el bienestar de los pueblos.

Juan Manuel Guerra estudia desde la Antropología los aportes del filósofo ecuatoriano Bolivar Echeverría y sus reflexiones en torno a la identidad. A partir de ello discute uno de los principios de la modernidad capitalista que es el surgimiento de la identidad a partir del trabajo como creador de civilidad. Trabajar para ser, es un principio orientador en sociedades con diferente nivel de desarrollo, por ello, en referencia a sociedades en este continente, el trabajo no es únicamente el medio por el cual el sujeto suprime la violenta impulsividad de su otredad, es también la forma desde la cual éste se enfrenta a la amenaza que la naturaleza supone para él. En la presencia contingencial y azarosa de esa amenaza, el trabajo humano puede adquirir diversas formas concretas o "compromisos históricos... capaces de convocar y juntar a seres humanos a través de cientos o incluso miles de años otorgándoles una individuación o identificación perdurable" (Echeverría, 2013:112). Formas específicas de trabajo o subcodificaciones de la forma trabajo-consumo que marcarían la pauta concreta para transformar la naturaleza con arreglo a las necesidades-deseos específicos de un grupo. Aquí, la otredad no deviene de la interioridad del sujeto, sino de la naturaleza misma (Echeverría, 2011) y de la diversidad de formas civilizatorias configuradas por el hombre frente a la escases-amenaza de la naturaleza.

Hablar de visualidad en Antropología es dar pie a un debate disciplinar necesario. Este número de Religación presenta tres trabajos a partir de la Antropología Visual (uno en Veracruz, otro en Quito y otro en Cotacachi) artículos que inciden en diversos campos del conocimiento que desde la antropológica clásica no habría sido posible.

Como lo discute Liliana León la metodología visual surge luego de una propuesta, que décadas atrás expusieran James Clifford y George Marcus (1986) como una crítica al verbocentrismo y al textualismo; y simultáneamente una invitación a expandir los diseños metodológicos en el trabajo de campo, está claro que para esta disciplina de la Antropología, no es suficiente con el documento escrito, pues estos no muestran el efecto de las expresiones corporales o colectivas del sujeto u objeto estudiado, como si lo hace el audiovisual. Además la visualidad no es un documento que sólo los cientistas pueden luego analizar y decodificar, sino que la imagen y sus contenidos son mejor deconstruidos e interpretados cuando simultáneamente el sujeto investigado también los mira y analiza. A partir de este entendido, Liliana León estudia la migración y la existencia de una colonia de cinco mil jubilados estadounidenses a Ecuador, un pequeño país del tercer mundo, donde ellos y ellas se retiran con sus pensiones a terminar sus días, en mejores condiciones que su país de origen. Pero claro ellos no se identifican como migrantes, que si lo son los tercermundistas, ellos son ExPad.

Desde la Antropología, lo visual, la visualidad, como herramienta desde la modernidad se vuelve fundamental para interpretar, reconstruir, de construir o desarrollar pensamiento, en y desde el sujeto estudiado, como lo hacen Antonio 
Bautista y Julieta Jaloma, dos indígenas de Veracruz que usan el dispositivo audiovisual para recuperar su memoria y fortalecer la identidad de estudiantes en varios institutos mexicanos. La visualidad es entonces herramienta de recolección e interpretación, pero a la vez sentido y orientación con sentido colectivo y comunitario. En Antropología, lo visual se orienta a mirar más allá, a repensar en lo que se ve, como se ve y como se piensa, no solo desde la imagen, sino detrás de ella y lo que no es evidente. Desde la Antropología, la herramienta de lo visual para reflexionar sobre si mismos, para hablar desde una propia mirada, construida y pensada desde y por quienes desarrollan ciencia social. Una mirada propia que no busca colonizar, exotizar o culturizar a la ciencia social.

En este orden de ideas, Jhon Viazus trabaja la Visualidad y pone atención en el espacio público como proceso dinámico y conflictivo en donde la práctica graffitera es generadora de una estética urbana particular que evidencia tanto procesos ligados a la segregación espacial como concepciones elitizadas de dicha estética. De ahí que analiza la imagen no solo como producto estético, sino también, desde la pertenencia social de quien la crea y diseña, de esta manera desde lo visual se aporta a la identidad de las imágenes y de quienes las imaginan, para luego, en actos de irreverencia pintarlos en paredes y fachadas.

Desde la Antropología Política se encuentra diversos aportes al debate actual. El aporte metodológico de esta disciplina se expresa en ubicar nuevas formas de poner en práctica la memoria como activadora de sentidos y a la vez como instrumento político para recuperar social, simbólica y efectivamente territorios. Así como se vuelve en escenario donde se cuestiona la política desde espacios centrales y centralizados que desconocen la vibrante construcción política desde espacios subalternos alejados de la centralidad.

La memoria se vuelve instrumento de política, así lo plantean Silvia Carina Valiente, Jorgelina Beatriz Bertea que estudian una población donde los efectos de la minería a gran escala trituraron no sólo la salud, sino la sociedad en su conjunto, de ahí que, la estrategia de activación de la memoria colectiva desde la metodología crítica, para la Antropología como ciencia desde el Sur, es una forma de "descolonizar la metodología", desanclando la reproducción del colonialismo epistémico y posibilitando otras versiones del pasado, además del empoderamiento de los grupos. La aplicación de la metodología tuvo por finalidad enfrentar la desmemoria a través del reposicionamiento de lógicas del lugar que permitan la planeación del mismo, habilitó un espacio para iniciar procesos de auto-reconocimiento de la comunidad territorial a partir de valorar y asumir la propia cultura como desatendida ante los intereses del estado.

En los testimonios presentados, es posible anunciar un decir crítico que cuestiona el poder y se revela a través del sentimiento de marginación, desposesión, abandono y postergación; sentires que habilitan un "pensamiento otro" (Escobar, 2003) y con ello, otras formas de pensar y estar en el mundo. En sintonía con ello, creemos que la memoria colectiva es de particular relevancia en la investigación social, tanto los relatos e interpretaciones del pasado (obturado por el orden colonial) proveen de sentido al presente y permiten definir un horizonte de posibilidades para la acción.

Por otro lado Juan Fernández estudia desde las herramientas antropológicas, la exclusión en un polígono en México, en un área marginada y con personas en constante tránsito como es la frontera entre México y Estados Unidos. Reclama 
con esto el lugar que tiene hacer políticas desde las periferias como esencia para construir cultura, sentidos y sociedad. Mientras la ciencia política clásica reconoce la importancia de actores institucionales para fijar y resolver los temas de una agenda pública, Fernández reconoce la capacidad creativa y resolutiva de agentes no institucionales, poblaciones organizadas de forma colectiva que reconoce un problema y condición en común. Las poblaciones excluidas no sólo padecen esa condición por aspectos económicos o espaciales, sino también una exclusión política. Se encuentran alejados de las oficinas de gobierno o de atención ciudadana, lo que complica su comunicación con el Estado y la gestión de soluciones, aunque sí participan de manera pasiva en la arena política, través del voto y de la demanda de líderes populares partidistas que no tienen ninguna injerencia institucional.

En consecuencia con la búsqueda de una Antropología comprometida en y desde este continente, Eliana Acosta Márquez, sugiere una antropología crítica para repensar el despojo de territorios. Para ella, defender al tierra es defender la imaginación y el derecho a vivir otros mundos posibles y desde esa visión sugiere un trabajo profesional comprometido con la vida. Bajo esa perspectiva, desde la academia es necesario generar enfoques de investigación críticos que dejen ver la complejidad de lo que está sucediendo. En particular, desde la etnografía, es necesario registrar las contradicciones y dar cuenta de la multidimensionalidad del despojo. Se alude a este término ya que los pueblos están siendo sustraídos de su base material de subsistencia, agua, cerros, semillas, animales, plantas, pero también poniendo en riesgo sus saberes, rituales, narrativas, cosmologías y de todo aquello que ha conformado su singularidad y diferencia.

Haciendo uso de herramientas de intervención, acompañamiento y trabajo con pacientes con VIH, desde la Antropología Aplicada, José Luis Nieto plantea una visión de la Antropología que cabe dentro de la disciplina médica, pero sobre todo de las prácticas colectivas para sobre llevar un padecimiento, a esto el autor denomina empoderamiento colectivo, que consiste en el intercambio grupal de saberes que tienen el potencial de generar comportamientos de adherencia simbólica. Las representaciones y prácticas compartidas grupalmente se relacionan con la necesidad de integración social, la liberación de sentimientos de culpa y el restablecimiento de las relaciones afectivas. De ahí que el empoderamiento colectivo constituye un trasfondo escénico o backstage (Goffman, 1997), en donde se aprenden las herramientas de adherencia simbólica y, por supuesto, terapéutica.

El conjunto de artículos ahora presentados ponen de manifiesto diversos aportes en la perspectiva de construir una ciencia social comprometida y transformadora. Pero no basta con ello, sino señalar que el común denominador de los artículos ahora presentados es una idea de sociedades con apuestas colectivas, con identidades que se piensan no sólo desde lo personal, sino que operan en función de principios colectivos. Lo colectivo como resistencia, como memoria, como cultura alimentaria, como lenguaje y visualidad. 
